McGrann, M. C., M. W. Tingley, J. H. Thorne, D. L. Elliott-Fisk, and A. M. McGrann. 2014. Heterogeneity in avian richness-environment relationships along the Pacific Crest Trail. Avian Conservation and Ecology 9(2): 8. http://dx.doi.org/10.5751/ACE-00695-090208

Copyright (C) 2014 by the author(s). Published here under license by the Resilience Alliance.

Research Paper

\title{
Heterogeneity in avian richness-environment relationships along the Pacific Crest Trail
}

\author{
Michael C. McGrann ${ }^{1,2}$, Morgan W. Tingley ${ }^{3,4}$, James H. Thorne ${ }^{5}$, Deborah L. Elliott-Fisk ${ }^{1}$ and Amy M. McGrann ${ }^{1,2}$ \\ ${ }^{1}$ Department of Wildlife, Fish, and Conservation Biology, University of California, Davis, ${ }^{2}$ Division of Natural and Applied \\ Sciences, Biology Department, William Jessup University, Rocklin, California, ${ }^{3}$ Woodrow Wilson School, Princeton University, \\ ${ }^{4}$ Department of Ecology and Evolutionary Biology, University of Connecticut, ${ }^{5}$ Department of Environmental Science and Policy, \\ University of California, Davis
}

\begin{abstract}
Predictions of the responses of montane bird communities to climate change generally presuppose that species and assemblages hold constant relationships to temperature across large study regions. However, comparative studies of avian communities exploring the factors that currently shape species richness patterns rarely analyze relationships across neighboring ecological regions of the same mountain chain. Evaluations of the intrinsic regional differences in species-environment relationships are needed to better inform expectations of how bird communities may be affected by future climate change. In this study, we evaluated the relative importance of three environmental factors (temperature, precipitation, and net primary productivity) in structuring avian richness patterns along a continuous mega-transect. We followed the route of the Pacific Crest Trail (PCT) $\left(32.58^{\circ} \mathrm{N}\right.$ to $42.00^{\circ} \mathrm{N}$, ranging in elevation from 365 to $4020 \mathrm{~m}$ ) on the California cordillera and completed avian point counts on 3578 systematically established survey plots. We divided this mega-transect into five sections, which corresponded to distinct ecological regions along the mountain chain. Regions differed both for elevation-richness patterns, exhibiting linear and unimodal trends, and for model-supported environmental drivers of patterns, with some richness-environment correlations changing sign across adjacent regions. These results were robust to sampling bias, regional species availability, and spatial autocorrelation. Although seasonal variation in avian movements may have limited influence on our results, we conclude that intrinsic regional environments affect bird species richness differently in each of these sections on the PCT, thus creating region-specific species-environment relationships. Appreciation of regional environmental heterogeneity will only increase in light of forecasted climate change, where regional predictions often diverge greatly from global trends, necessitating a site-specific approach to climate adaptation rather than 'one size fits all' strategies.
\end{abstract}

\section{Hétérogénéité des relations richesse aviaire-environnement le long du sentier des Crêtes du Pacifique}

RÉSUMÉ. Les prédictions des réactions des communautés d'oiseaux de montagne face aux changements climatiques supposent habituellement que les espèces et les assemblages d'oiseaux maintiennent une relation constante avec la température dans de grandes régions d'étude. Pourtant, les études comparatives de communautés aviaires qui explorent les facteurs à l'origine des profils de richesse aviaire analysent rarement les relations entre les régions écologiques voisines d'une même chaîne de montagnes. L'évaluation des différences régionales intrinsèques des relations espèces-environnement est nécessaire si l'on veut mieux prévoir comment les communautés d'oiseaux pourraient être affectées par les futurs changements climatiques. La présente étude évalue l'importance relative de trois facteurs environnementaux (la température, les précipitations et la productivité primaire nette) à structurer les profils de la richesse aviaire le long d'un mégatransect continu. Nous avons parcouru le sentier des Crêtes du Pacifique (en anglais Pacific Crest Trail, PCT) (du $32,58^{\circ} \mathrm{N}$. au 42,00 N.; de 365 à $4020 \mathrm{~m}$ d'altitude) sur la cordillère californienne et avons réalisé des points d'écoute dans 3578 parcelles d'inventaire réparties systématiquement. Nous avons divisé le mégatransect en cinq sections qui correspondent à des régions écologiques distinctes sur la chaîne de montagnes. Les régions ont différé sur deux plans : d'une part, sur celui des profils altitude-richesse, qui montraient des tendances linéaire et unimodale et, d'autre part, sur celui des facteurs environnementaux qui agissaient sur les profils et que les modèles ont validés. Certaines régions adjacentes ont montré des corrélations richesse-environnement opposées. Ces résultats étaient robustes aux biais d'échantillonnage, la disponibilité aviaire régionale et l'autocorrélation spatiale. Même si les variations saisonnières des déplacements aviaires ont pu avoir un effet limité sur nos résultats, nous concluons que l'environnement régional intrinsèque affecte la richesse en espèces d'oiseaux de façon différente dans chacune des sections du PCT et crée ainsi des relations espèces-environnement régionalement spécifiques. L'estimation de l'hétérogénéité environnementale régionale ne s'améliorera qu'en fonction des prévisions relatives aux changements climatiques, sachant que les prédictions régionales divergent souvent grandement des tendances globales, ce qui explique que l'adaptation climatique requiert une approche spécifique au site plutôt que des stratégies « universelles ».

Key Words: birds; California; elevation gradient; mega-transect; net primary productivity; precipitation; species richness; temperature

Address of Correspondent: Michael C. McGrann, William Jessup University, Natural and Applied Sciences Division, Biology Department, 333 Sunset Boulevard, Rocklin, California 95765 USA, Michael.McGrann@gmail.com 


\section{INTRODUCTION}

Mountainous regions are hotspots of avian diversity (Ruggiero and Hawkins 2008) that are expected to be highly sensitive to climate change (La Sorte and Jetz 2010). In California, studies of ongoing climate change indicate that montane birds are already responding by shifting their elevation ranges (Tingley et al. 2012) and that long-term effects include richness declines and high community turnover (Tingley and Beissinger 2013). Despite evidence for location-specific sensitivity of species to different climatic factors (Tingley et al. 2009, 2012), range predictions of montane birds, given climate change, generally assume species and communities respond universally to climate across their range (Sekercioglu et al. 2008, Stralberg et al. 2009, Wiens et al. 2009, Anderson et al. 2013). Some regional studies of avian speciesenvironment relationships appear to provide partial support of this assumption, particularly for large regions with relatively low topographic relief and homogenous habitat (DesGranges and LeBlanc 2012). On mountains, environmental variables change with elevation over relatively short distances. These steep gradients provide opportunities to conduct observational and comparative studies of the environmental drivers of avian diversity (Körner 2007). These types of studies can inform avian conservation efforts because they can identify both the relative importance of different environmental factors in driving species diversity as well as the universality, or regional heterogeneity, of environmental drivers of diversity among neighboring regions (Rowe 2009). Despite the potential contributions of studies in mountain systems to increase our understanding of avian ecology and conservation, systematic efforts that gather field data at a macroecological scale have been rare in these remote regions. Here, we survey avian richness continuously along the Pacific Crest Trail (PCT) through five distinct mountain regions that together form the California cordillera. We ask how speciesenvironment relationships change along the PCT through each of these sections, providing inference on how climate may differentially structure communities across adjacent ecological regions.

The topography of California is dominated by a massive northsouth oriented cordillera, which supports a rich avifauna because of the presence of strong, overlapping gradients in temperature (south to north with latitude and low to high with elevation) and precipitation (south to north and east to west with a rain shadow effect). Significant changes in temperature and precipitation are projected for California by the end of the 21 st century. Temperature is projected to increase by 2 to $5^{\circ} \mathrm{C}$ across the state (Snyder et al. 2002) and although there is less agreement among climate models on the direction of precipitation change (IPCC 2007), there is more agreement that the proportion of precipitation that falls as rain will increase, while snowfall will decrease. These climatic changes may have a profound effect on birds and their habitats (Siegel et al. 2014), by altering plant productivity, vegetation structure, and plant species composition, including a projected loss of 50 to $90 \%$ of subalpine and alpine habitats by the year 2099 (Hayhoe et al. 2004). Some climaticinduced habitat changes are already occurring on California's mountains (Thorne et al. 2008, Dolanc et al. 2013). The magnitude of these climate projections makes more urgent the need for studies that clarify species-environment relationships, particularly in California's mountain regions.
Our ability to test for region-specific species-environment relationships in California is informed by the strong role that mountains have played globally in testing environmental hypotheses for elevation species richness patterns (Sanders and Rahbek 2012). Described patterns of elevation richness include increasing, decreasing, and most commonly, unimodal trends (Rahbek 2005), where maximum species richness occurs at some intermediate elevation. Ecologists and biogeographers have sought to elucidate species-environment relationships on mountains and found that many factors may correlate with avian richness, including past and present climate, geologic and evolutionary history, topography, biological interactions, habitat distribution, and human disturbance patterns (Lee et al. 2004, Ruggiero and Hawkins 2008, Sanders and Rahbek 2012). Perhaps the most widespread support can be found for temperature, net primary productivity, and precipitation as correlates of avian richness on mountains (McCain 2009). Temperature can limit bird distributions by exceeding physiological tolerances and both temperature and precipitation strongly limit plant growth and influence the amount of biomass available to consumers in an ecosystem. Although the relationship between temperature, precipitation, and productivity with avian richness has been examined at the global scale (Hawkins et al. 2003, McCain 2009) and several energy-related underlying mechanisms for this relationship have been proposed and tested (Evans et al. 2005, Honkanen et al. 2010), it remains unknown how these three factors differentially relate to avian richness along latitudinal and elevation gradients among adjacent mountain regions.

Given that region-specific environmental characteristics can differentially correlate with richness (Rowe 2009), our goal was to examine whether and how species-environment relationships change across adjacent regions. We surveyed local avian richness on the PCT through five adjoining mountain regions. Our objectives were (1) to quantify avian richness patterns along elevation gradients on the PCT in each region and (2) to compare the relative strength of these three factors as correlates with richness among the five regions, while simultaneously accounting for several inferential challenges, including sampling effects, spatial autocorrelation, and the regional species-pool. We used our observations to test the null hypothesis, typical of climate change predictions, that species richness-environment relationships show generality across neighboring ecoregions.

\section{METHODS}

\section{Study area}

The PCT extends across a series of mountain ranges from the international borders with Mexico to Canada, across the states of California, Oregon, and Washington. The California section $\left(\sim 2736 \mathrm{~km}, 32.58^{\circ} \mathrm{N}\right.$ to $\left.42.00^{\circ} \mathrm{N}\right)$ served as a mega-transect along which we surveyed birds at regular intervals (Fig. 1a). The PCT is a recreational hiking and equestrian trail through remote habitats, spanning elevations from $365 \mathrm{~m}$ in southern California to $4020 \mathrm{~m}$ in the southern Sierra Nevada. Along the California cordillera, total annual precipitation generally increases from south to north (Fig. 1c). It follows a contouring route along the relatively wet and windward, western-facing slopes of the cordillera, and to a lesser extent, it also occurs on drier and leeward, eastern-facing slopes. In southern California, it crosses 
Fig. 1. Relationships of environmental variables with latitude and elevation across the Pacific-Crest Trail (PCT) within California. (a) Map showing the extent of the mega-transect in California and locations of the five regional sections of the PCT. The black line indicates the route of the PCT. Graphs depict underlying environmental gradients in (b) average maximum annual temperature (Tmax), (c) total annual precipitation (Precip), and (d) maximum seasonal Normalized Difference Vegetation Index (NDVI ${ }_{\max }$ ) across all point count sites. Dotted lines in graphs indicate latitudinal cutoffs for each region. SoCa: southern California, SoSN: southern Sierra Nevada, NoSN: northern Sierra Nevada, Casc: southern Cascades, and Klam: Klamath Mountains.

(a)

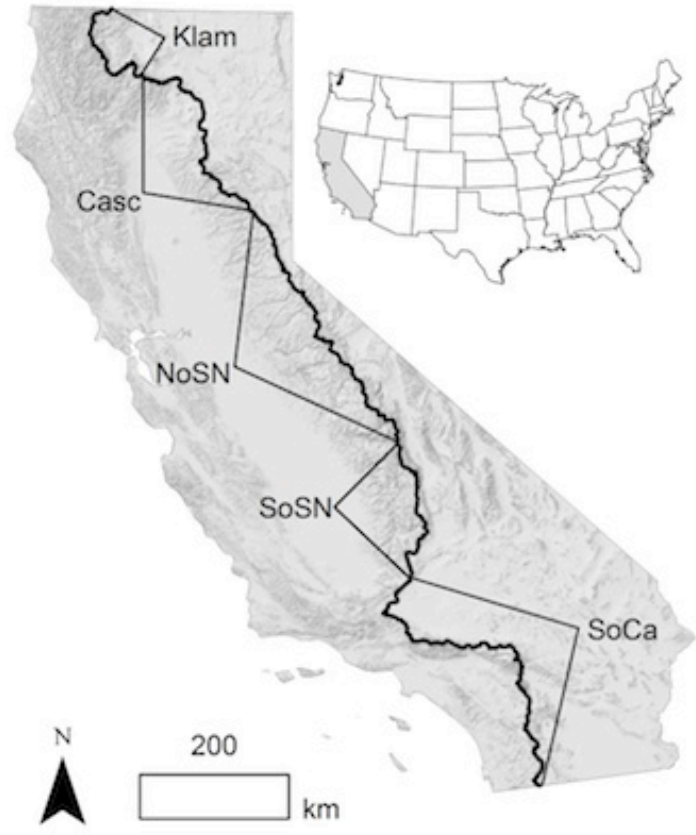

(c)

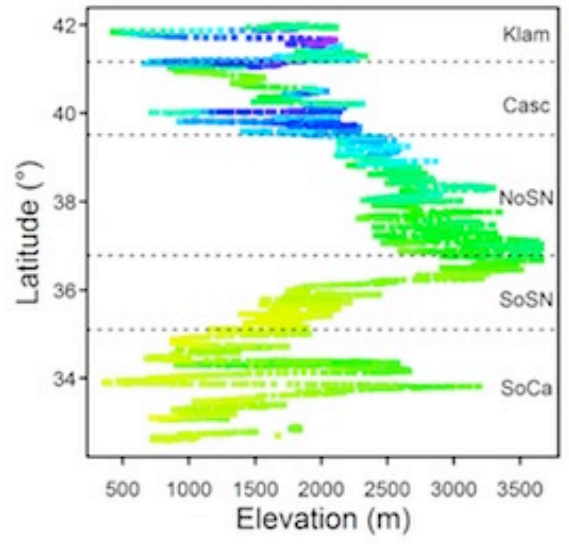

(b)

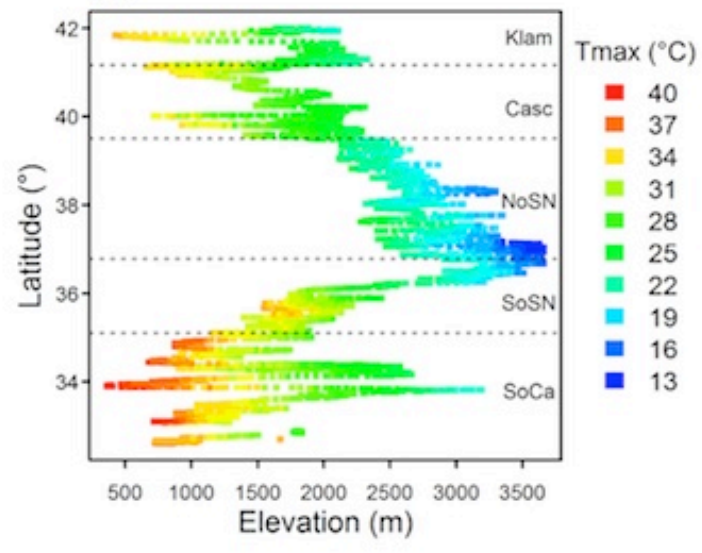

(d)

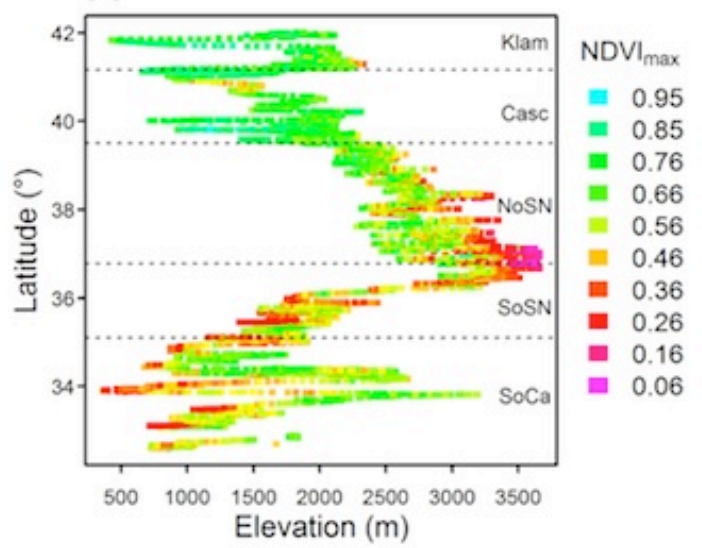

portions of the Mojave and Colorado Deserts. Thus, the PCT route encounters a wide range of habitat types, including desert scrub, grassland, chaparral, woodland, forested, and alpine habitats (California Department of Fish and Wildlife 2008). We divided the mega-transect into sections that corresponded to five, climatically and geologically distinct, ecological regions: southern California (SoCa), southern Sierra Nevada (SoSN), northern Sierra Nevada (NoSN), southern Cascades (Casc), and Klamath
Mountains (Klam). With some modification, we defined our sections based on the boundaries for California ecological regions defined by Miles and Goudey (1997). The sampled length of the elevation gradients varied among these sections and was determined by the elevation profile of the PCT route itself through each region as well as the overall topographic relief of each mountain range. 


\section{Bird surveys}

Birds were surveyed according to a spatially and temporally standardized protocol at survey plots on a single visit. One observer (MCM) systematically stopped at 10-minute walking intervals (approximately, every $500-700 \mathrm{~m}$ ) along the PCT and conducted 5-minute point counts of birds on fixed-radius, $50-\mathrm{m}$ circular plots. All bird species and individuals seen or heard within each plot were counted. A total of 3578 point counts were completed across the $2736 \mathrm{~km}$ length of the PCT in California in a single field season (2006), resulting in local richness estimates for each of the plots. A second observer (AMM) assisted with data recording and conducted a rapid habitat assessment.

We followed the methodology for fixed-radius point counts (Ralph et al. 1995), except in two key respects. First, instead of restricting counts to the morning hours, surveys were conducted from dawn to dusk. Second, we surveyed from 2 April to 8 September 2006, when most California migrant birds were present in summer habitats, but before the return of migrants to wintering grounds (McGrann and Thorne 2014). Surveys along each of the five regional sections of the PCT were completed within a narrower time frame: SoCa (2 April - 27 May), SoSN (29 May 20 June), NoSN (8 August - 8 September), Casc (26 June - 20 July), and Klam (20 July - 4 August). Although surveying throughout the day and throughout the summer served to maximize data collection in remote landscapes, several montane birds in California have complex diurnal and seasonal behavior and movements (McGrann and Thorne 2014). We explicitly accounted for time-of-day and time-of-year when building our models because these factors may influence the number of species detected.

\section{Environmental data}

We used the spatial analyst extension in ArcGIS (version 10, Environmental Systems Research Institute, Redlands, California, USA) to extract elevation, temperature, precipitation, and productivity variables from gridded data sources at survey points. Elevations came from the National Elevation Dataset $(10 \mathrm{~m}$ resolution; U. S. Geological Survey, http://ned.usgs.gov). Spatial grids $(1 \times 1 \mathrm{~km}$, or 30 arc-second resolution $)$ of temperature and precipitation for 2006 were obtained for California using the Parameter-elevation Relationships on Independent Slopes Model (PRISM). PRISM data are particularly good at predicting the diverse climates across mountainous regions (Daly et al. 2008). From the spatial grids, we extracted average annual maximum, minimum, and mean temperature $\left({ }^{\circ} \mathrm{C}\right)$ and total precipitation $(\mathrm{mm})$ in 2006 for each point count location.

We used the satellite-derived Enhanced Vegetation Index (EVI) and Normalized Difference Vegetation Index (NDVI) as proxies of net primary productivity. Spatial grids (250-m resolution) of 16-day composites of EVI and NDVI for 2006 were derived from the Moderate Resolution Imaging Spectroradiometer (MODIS) and obtained from the Land Processes Distributed Active Archive Center (http://lpdaac.usgs.gov). NDVI is calculated from the reflectance of red and near-infrared spectral bands, which is associated with healthy green vegetation. EVI includes adjustments for soil and atmospheric aerosol scattering and both EVI and NDVI serve as good proxies of plant biomass (Jensen 2007). For each bird point count location, we extracted two EVI and NDVI variables: the specific value from the 16-day composite grid that corresponded with the date of the point count survey, and the maximum value over the entire field season in which the surveys were conducted.

\section{Models of richness}

We tested the relative importance of temperature, precipitation, and net primary productivity variables as predictors of observed bird richness using Generalized Linear Models (GLM) with a negative binomial distribution to account for overdispersed count data. All analyses were conducted in $\mathrm{R}$ version 3.0.3 ( $\mathrm{R}$ Development Core Team 2014) and all models were run using the package "MASS" (Venables and Ripley 2002). Variable selection was conducted during an initial exploratory phase, followed by multimodel comparison. In all cases, model or variable support was measured by the Akaike Information Criterion (AIC, Burnham and Anderson 2002). Although attempts were made to reduce multicollinearity of variables in models, model coefficients of all top models were also inspected for variance inflation and stability in the presence of other covariates.

In the exploratory phase, richness models were constructed to compare support for different predictor variables within the same environmental hypothesis class, i.e., temperature, precipitation, and net primary productivity. Within each hypothesis class, data from the entire study area were combined to test the relative importance of each variable across all five regions. Temperature models compared average annual minimum temperature $\left(T_{\min }\right)$, maximum temperature $\left(T_{\text {max }}\right)$, and mean temperature $\left(T_{\text {mean }}\right)$, as well as squared effects. Precipitation models compared total annual precipitation $(P)$ and squared effects. Productivity models compared maximum $\operatorname{EVI}\left(E V I_{\max }\right)$ and NDVI $\left(N D V I_{\max }\right)$ for the entire field season and EVI $\left(E V I_{t}\right)$ and NDVI $(N D V I)$ on the survey date as well as squared effects. Each exploratory model contained a single environmental predictor variable (or two variables, for squared effects). In addition to the temperature, precipitation, or net primary productivity variables, all exploratory models contained time-of-year, time-of-day (including squared effects), and regional species pool as independent variables. By accounting for time-of-day and timeof-year explicitly within models, we acknowledge that these observation data attributes may affect the number of species observed at a single survey point. Regional species pool was included in models because the available pool of species is generally accepted to structure local richness estimates (Ricklefs 2000). Following White and Hurlbert (2010), the regional species pool at each location was estimated by intersecting survey points with range maps from the California Wildlife Habitat Relationships System (California Department of Fish and Wildlife 2008) for all 155 detected bird species (Appendix 1). Independent variables were normalized to a mean of zero and a standard deviation of one. Within each environmental class of variables (temperature, precipitation, or net primary productivity), the individual variable parameterization that was best supported by the data (lowest AIC) was used in the following multimodel comparison to understand region-specific differences in richness relationships.

In the second analysis phase, richness was modeled as a function of the three environmental hypothesis classes for each of the five regional sections on the PCT. Eight GLM models were constructed, which independently and additively tested the three 
best-supported parameterizations from the exploratory analysis, as well as a null model, i.e., no environmental covariates. All models contained the same sampling-based independent variables (time-of-day, time-of-year, and regional species pool) as the exploratory analysis and used a negative binomial error distribution with a log-link.

To investigate how the three environmental hypothesis variables may be differentially supported among each of the five regions, region-specific models were compared using AIC and AIC weights $\left(w_{i}\right)$. Impact factors (IF), which are cumulative AIC weights in support of an individual variable, were calculated for each of the three classes of variables for each region, to test for shifting support of temperature, precipitation, or net primary productivity predictors across all five regions of the PCT (Burnham and Anderson 2002). IF scores of 1 indicated universal support, scores above 0.8 indicated strong support, and scores below 0.5 indicated weak support.

Because differing support for environmental relationships within regions may arise from incomplete overlapping of sampled environmental gradients across regions, a third analysis phase focused on region-specific environmental relationships within a model that included data from the entire Californian megatransect. An initial, baseline model included temperature, NDVI, and precipitation, matching the "full" model for the second phase of the analysis but combining data from all regions. Eight subsequent models tested for region-specific differences of environmental relationships within this baseline model: (1) a model with region added as a categorical variable; (2-4) models that separately tested for interactions between each region and temperature, precipitation, and NDVI; (5-7) models that tested for interactions between region and two of the three environmental variables; and (8) a model that included interactions between each region and all three environmental variables. Similar to previous analysis stages, all models were compared with AIC and the top model was examined for significant covariate effects.

To explore relationships of elevation with richness in our dataset, we estimated observed elevation richness maxima via GLMs. For each region, we modeled observed richness as a Poissondistributed function of elevation, including quadratic effect. Elevations of maximum richness were identified from these modeled relationships.

\section{Tests of spatial autocorrelation and inferential challenges}

We tested the degree to which spatial autocorrelation was present in both our raw richness values and our model residuals (White and Hurlbert 2010). For each of the five ecological regions, we created spatial correlograms by calculating Moran's I (Zuur et al. 2007) with distance lags of $50 \mathrm{~km}$. Significant correlations $(p<$ 0.01 ) were determined through resampling 1000 permutations. Analyses were conducted in R using the package "ncf" version 1.1-4 (Bjornstad 2012).

In addition to spatial autocorrelation, a number of other factors can influence counts of local richness, potentially biasing parameter estimates. In many cases, patterns derived from observed richness may differ from true patterns because of sampling bias (Gotelli and Colwell 2001). Although true richness could not be estimated because multiple samples were not collected for most sites, we accounted for potential sampling bias directly by including sampling variables in our models, e.g., timeof-day, time-of-year. Additionally, in a subsequent year (2007), a subsample of high-elevation sites were revisited and surveyed in three consecutive increments for 120 minutes total. This supplemental data allowed a partial evaluation of the completeness of the 5-minute surveys (Appendix 2).

\section{RESULTS}

Bird surveys detected 155 bird species, comprising 21,599 individuals and totaling 13 orders, of which $68 \%$ of the species belonged to Passeriformes. The exploratory phase in the analysis revealed strongly supported richness parameterizations (Table 1) within each of the three classes of environmental variables (temperature, precipitation, and productivity). $T_{\max }$ with squared effect was the best supported temperature model $\left(w_{i}=1.0\right)$, while $P$ (linear-only) was the best supported precipitation model $\left(w_{i}=\right.$ 0.73 ), and $N D V I_{\max }$ with squared effect was the best supported productivity model $\left(w_{i}=0.70\right)$. These three parameterizations were used in subsequent model comparisons of richness relationships.

Table 1. Parameter selection for each of three environmental hypothesis categories, ranked by AIC weight $\left(\mathrm{w}_{\mathrm{i}}\right)$.

\begin{tabular}{lccc}
\hline \hline Category & Parameter $^{\dagger}$ & $\Delta \mathrm{AIC}^{\ddagger}$ & $w_{i}$ \\
\hline Temperature & $T_{\max }{ }^{2}$ & 0.00 & 1.00 \\
- & $T_{\min }{ }^{2}$ & 35.57 & 0.00 \\
- & $T_{\operatorname{maan}}{ }^{2}$ & 40.96 & 0.00 \\
- & $T_{\max }$ & 206.22 & 0.00 \\
- & $T_{\operatorname{mean}}$ & 213.07 & 0.00 \\
- & $T_{\min }$ & 216.08 & 0.00 \\
Precipitation & $P$ & 0.00 & 0.73 \\
- & $P^{2}$ & 1.99 & 0.27 \\
Productivity & $N D V I_{\max }{ }^{2}$ & 0.00 & 0.70 \\
- & $N D V I_{t}^{2}$ & 1.66 & 0.30 \\
- & $E V I^{2}$ & 109.43 & 0.00 \\
- & $E V I_{\max }{ }^{2}$ & 137.06 & 0.00 \\
- & $N D V I_{\max }$ & 143.49 & 0.00 \\
- & $E V I_{\max }$ & 153.85 & 0.00 \\
- & $N D V I_{t}$ & 203.66 & 0.00 \\
- & $E V I_{t}$ & 222.13 & 0.00 \\
\hline \hline
\end{tabular}

Environmental hypothesis parameters were tested using both linear and quadratic forms. Within quadratic models (signified by ${ }^{2}$ ), linear terms were also included.

"All models fit using Generalized Linear Models (negative binomial error distribution, log-link). Other model covariates included time-ofday (including squared), day-of-year (including squared), and size of regional species pool.

Species richness models that tested multiple environmental hypotheses simultaneously showed support for multiple factors as correlates with richness that changed inter-regionally (Tables 2, 3). In the SoCa, Casc, and Klam regions along the PCT, temperature was strongly supported as a factor structuring richness patterns. The relationship of richness with temperature for these regions was generally negative: as temperatures decreased with increasing elevation, richness increased. In the two Sierran regions as well as $\mathrm{SoCa}$, productivity $\left(N D V I_{\max }\right)$ received full model support with maximum richness associated with values 
Fig. 2. Modeled relationship and effect size of environmental (A-C) and sampling (D-F) factors associated with observed avian richness at point counts across each sampled region along the Pacific-Crest Trail. Relationships derived from each region's best supported Generalized Linear Models (GLM) and show parameter means while controlling for mean conditions of all other covariates. SoCa: southern California mountains, SoSN: southern Sierra Nevada, NoSN: northern Sierra Nevada, Casc: southern Cascade Range, and Klam: Klamath Mountains.

A.

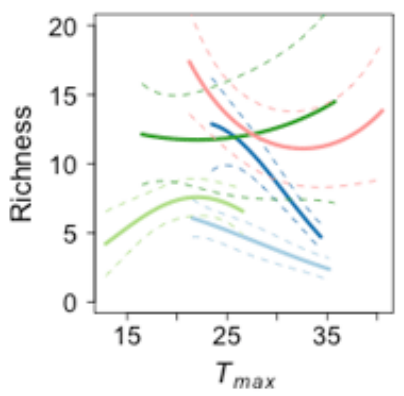

D.

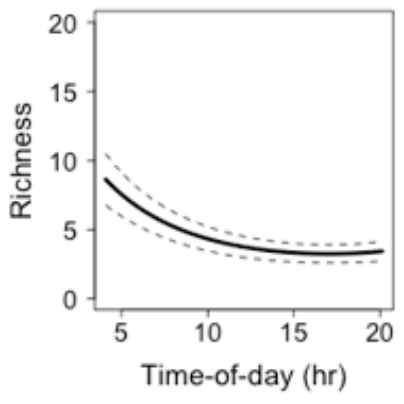

B.

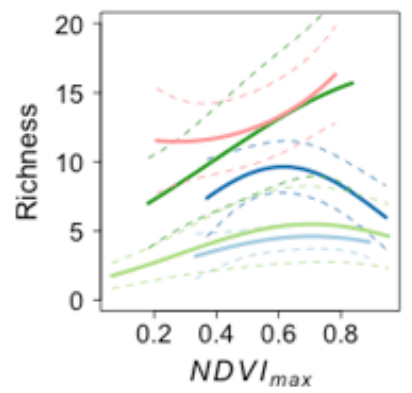

E.

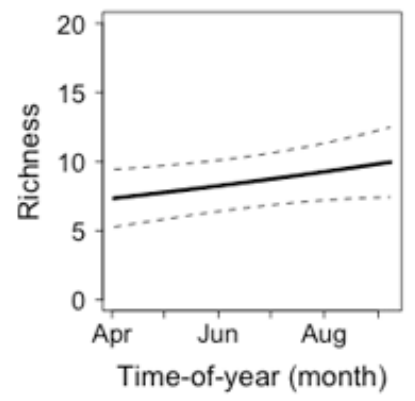

c.

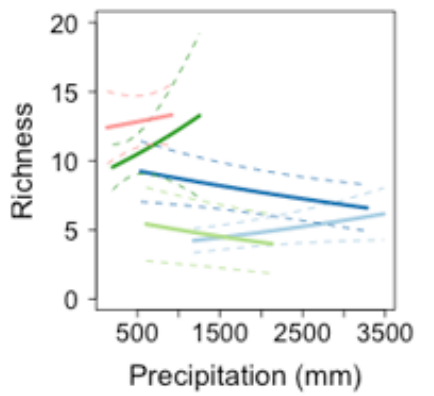

F.

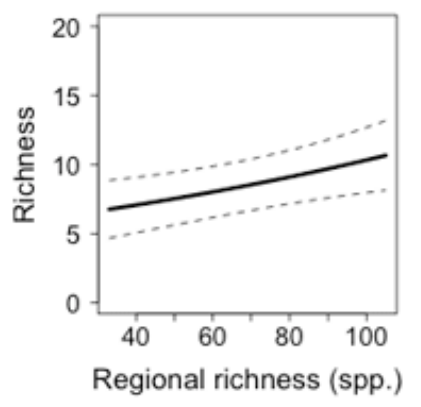

Table 2. Individual model AIC weights, by region, for additive and single-variable models testing the ability of different environmental hypotheses to explain observed avian richness.

\begin{tabular}{llccccc}
\hline \hline Response & Model $^{\dagger}$ & SoCa $^{\ddagger}$ & SoSN & NoSN & Casc & Klam \\
\hline Richness & Null & 0.00 & 0.00 & 0.00 & 0.00 & 0.00 \\
- & $T_{\max }^{2}$ & 0.00 & 0.00 & 0.00 & 0.00 & 0.09 \\
- & $P$ & 0.00 & 0.00 & 0.00 & 0.00 & 0.00 \\
- & $N D V I_{\max }{ }^{2}$ & 0.01 & 0.50 & 0.01 & 0.00 & 0.00 \\
- & $T_{\max }{ }^{2}+P$ & 0.00 & 0.00 & 0.00 & 0.66 & 0.57 \\
- & $T_{\max }+N D V I_{\max }{ }^{2}$ & 0.72 & 0.19 & 0.01 & 0.00 & 0.05 \\
- & $P_{+}+N D V I_{\max }^{2}$ & 0.01 & 0.19 & 0.57 & 0.00 & 0.00 \\
- & $T_{\max }{ }^{2}+N D V I_{\max }{ }^{2}$ & 0.26 & 0.12 & 0.41 & 0.33 & 0.29 \\
& $+P$ & & & & & \\
\hline
\end{tabular}

${ }^{\dagger}$ All models fit using negative binomial Generalized Linear Models. Other covariates included in each model were regional species pool effect, time-of-day (including squared), and day-of-year (including squared).

'SoCa: southern California mountains, SoSN: southern Sierra Nevada, NoSN: northern Sierra Nevada, Casc: southern Cascade Range, and Klam: Klamath Mountains.

between 0.5 and 0.8 . Precipitation received full model support in Casc, and strong support in NoSN (IF = 0.98) and Klam (IF = 0.86 ). The linear relationship of richness with precipitation was
Table 3. Impact factors ${ }^{\dagger}$ (cumulative AIC weights) indicating weight of evidence in support for different richness-structuring hypotheses for each region.

\begin{tabular}{llccccc}
\hline \hline Response & Variable & SoCa $^{*}$ & SoSN & NoSN & Casc & Klam \\
\hline Richness & Temperature & 0.98 & 0.31 & 0.42 & 1.00 & 1.00 \\
- & Precipitation & 0.27 & 0.31 & 0.98 & 1.00 & 0.86 \\
- & Productivity & 1.00 & 1.00 & 1.00 & 0.34 & 0.34 \\
- & IF total $^{\S}$ & 2.25 & 1.62 & 2.40 & 2.33 & 2.20 \\
\hline
\end{tabular}

Impact factors range from 0 to 1 , with 0 indicating no multi-model support for a variable, and 1 indicating full multi-model support for a variable. As multiple variables can be supported simultaneously, multiple variables can have an IF value of 1 .

SoCa: southern California mountains, SoSN: southern Sierra

Nevada, NoSN: northern Sierra Nevada, Casc: southern Cascade Range, and Klam: Klamath Mountains.

${ }^{\S}$ The IF total is the sum of IF scores across evaluated variables. Total values represent the consensus number of evaluated variables supported across multiple models.

negative in the adjoining regions of $\operatorname{NoSN}\left(\beta_{P}=-0.22 \pm 0.07\right)$ and Casc $\left(\beta_{P}=-0.16 \pm 0.03\right)$, yet was positive in Klam $\left(\beta_{P}=0.12\right.$ $\pm 0.04)$, despite the three regions having similar variation in precipitation across the sampled gradient (Figs. 1c, 2c). 
Within a single model using data from all regions, multimodel analysis confirmed that there were significant region-specific relationships of richness with each environmental variable. Among the nine models examining region-specific interactions, the top model contained interaction effects for all three variables: $T_{\max }, N D V I_{\max }$, and $P$ (Table 4). Close examination of this particular model showed significant interactions, relative to a baseline contrast of Casc, of SoCa and SoSN with $T_{\max }$, of Klam with $P$, and of SoCa with $N D V I_{\max }$ (Table 5). The modeled relationships indicated that the two southernmost regions showed increases at high $T_{\max }$ while the two northernmost regions had decreases with $T_{\max }$ (Fig. 2A), that SoCa had richness that increased at high $N D V I_{\max }$ unlike other regions (Fig. 2B), and that richness increased with precipitation in Klam, whereas it decreased for Casc (Fig. 2C). Although not all regions were sampled on the exact same extent of environmental gradients, significant region-specific interactions contrasted with at least one other region that did overlap in environmental space (Fig. 2).

Table 4. Multimodel comparison of different combinations of models that test for interactions between environmental variables and Sierra Nevadan regions.

\begin{tabular}{|c|c|c|}
\hline Model $^{\dagger}$ & $\Delta \mathrm{AIC}^{*}$ & $w_{i}$ \\
\hline region x $\left(T_{\max }^{2}+P+N D V I^{2}{ }^{2}\right)$ & 0.0 & 0.92 \\
\hline region $\mathrm{x}\left(T_{m a x}^{\max }+P\right)+N D V I I^{2}$ & 4.9 & 0.08 \\
\hline region x $\left(T^{\max }{ }_{2}+N D V I^{2}{ }^{2}\right)+\stackrel{\max }{P}$ & 12.0 & 0.00 \\
\hline region $\mathrm{x} T_{\max ^{2}}+P+N D V I_{\max }{ }^{2}$ & 27.8 & 0.00 \\
\hline 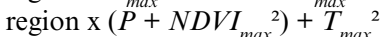 & 84.3 & 0.00 \\
\hline region $\mathrm{x} N D V I_{\max }{ }^{2}+T_{\max }^{2}+\mathrm{P}^{\max }$ & 95.1 & 0.00 \\
\hline 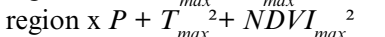 & 139.5 & 0.00 \\
\hline region $+T^{2}{ }^{2}+P+N D V I I^{\max } 2$ & 150.3 & 0.00 \\
\hline$T_{\max }^{2}+P+N D V I_{\max }^{2}$ & 212.9 & 0.00 \\
\hline
\end{tabular}

${ }^{\dagger}$ Environmental parameters signified by ${ }^{2}$ also include linear terms. ${ }^{\star}$ All models fit using Generalized Linear Models (negative binomial error distribution, log-link). Other model covariates included time-ofday (including squared), day-of-year (including squared), and size of regional species pool.

Observed avian richness exhibited region-specific variance in form (Fig. 3). Unlike modeled relationships with environmental gradients, which were generally quadratic in form (Fig. 2), relationships with elevation within each region were monotonic with the exception of SoSN (Fig. 3). For three regions, the trend of observed richness with elevation peaked at the highest sampled sites $(\mathrm{SoCa}=3194 \mathrm{~m}, \mathrm{Casc}=2312 \mathrm{~m}$, and Klam $=2331 \mathrm{~m})$. The two Sierra Nevadan regions showed richness maxima in the middle and lower-middle of their elevation sampling profiles $(\mathrm{SoSN}=2425 \mathrm{~m} ; \mathrm{NoSN}=2117 \mathrm{~m})$.

Our top richness model, including region-specific interactions, showed little effect of spatial autocorrelation on residuals (Fig. 4). In comparison, raw richness values showed significant patterns of spatial autocorrelation. Although the richness model reduced spatial autocorrelation at all distance classes, significant correlation in residuals remained at $50 \mathrm{~km}$, and between $600-800$ $\mathrm{km}$, the scale at which biogeographical differences can influence richness. Overall, magnitudes of correlation coefficients were low, however, with no model of residuals having a significant correlation exceeding \pm 0.1 .
Table 5. Parameter estimates, standard errors, and statistical significance for the top model explaining observed bird richness as a function of environmental factors and regional interactions.

\begin{tabular}{|c|c|c|c|}
\hline Parameter $^{\dagger}$ & Estimate & Std. Error & P-value \\
\hline (Intercept) & 2.851 & 0.230 & $<0.001$ \\
\hline Day-of-year & 0.002 & 0.001 & $<0.001$ \\
\hline Time-of-day & -0.003 & 0.000 & $<0.001$ \\
\hline Time-of-day $^{2}$ & 0.000 & 0.000 & 0.886 \\
\hline Regional Richness & 0.112 & 0.030 & 0.818 \\
\hline$T_{\max _{3}}$ & -0.409 & 0.089 & 0.062 \\
\hline$T_{\max }^{\max _{2}}$ & -0.216 & 0.087 & $<0.001$ \\
\hline$P^{\max }$ & -0.092 & 0.037 & $<0.001$ \\
\hline$N D V I_{\max _{2}}$ & 0.042 & 0.064 & $<0.001$ \\
\hline$N D V I_{\max }$ & -0.106 & 0.044 & 0.013 \\
\hline region:Klam ${ }^{\ddagger}$ & -0.921 & 0.117 & 0.014 \\
\hline region:NoSN & -0.599 & 0.166 & 0.514 \\
\hline region:SoCa & -0.015 & 0.105 & 0.016 \\
\hline region:SoSN & 0.047 & 0.204 & 0.000 \\
\hline region:Klam x $T_{\max }$ & 0.046 & 0.111 & 0.679 \\
\hline region:NoSN x $T_{\max }^{\max }$ & -0.023 & 0.272 & 0.933 \\
\hline region:SoCa x $T_{m a x}$ & 0.214 & 0.106 & 0.043 \\
\hline region:SoSN x $T$ & 0.478 & 0.105 & $<0.001$ \\
\hline region:Klam x $T_{m a x_{2}}$ & 0.147 & 0.123 & 0.234 \\
\hline region:NoSN x $T_{m a}$ & -0.002 & 0.141 & 0.989 \\
\hline region:SoCa x $T_{\max }$ & 0.325 & 0.093 & 0.000 \\
\hline region:SoSN x $T_{\max }$ & 0.251 & 0.099 & 0.011 \\
\hline region:Klam x $P$ & 0.214 & 0.060 & $<0.001$ \\
\hline region:NoSN x $P$ & -0.058 & 0.070 & 0.409 \\
\hline region:SoCa $\times P$ & 0.159 & 0.128 & 0.213 \\
\hline region:SoSN x $P$ & 0.326 & 0.198 & 0.100 \\
\hline region:Klam x $N D V I_{m a x}$ & 0.059 & 0.099 & 0.553 \\
\hline region:NoSN x $N D V I_{\max }$ & 0.061 & 0.071 & 0.385 \\
\hline region:SoCa x $N D V I_{\max }$ & 0.090 & 0.070 & 0.203 \\
\hline region:SoSN x $N D V I$ & 0.122 & 0.087 & 0.159 \\
\hline region:Klam x $N D V I_{\max }$ & 0.041 & 0.071 & 0.560 \\
\hline region:NoSN x $N D V I_{\max }$ & 0.039 & 0.049 & 0.423 \\
\hline region:SoCa x $N D V I_{\max }$ & 0.139 & 0.051 & 0.007 \\
\hline region:SoSN x $N D V I_{\max }$ & 0.079 & 0.058 & 0.175 \\
\hline \multicolumn{4}{|c|}{$\begin{array}{l}\text { †For regional effects, Casc was used as the baseline versus which all } \\
\text { other regional contrasts were compared. Lines are bolded where } \\
\text { parameter-specific P-values were less than } 0.05 \text {. } \\
\text { "Klam: Klamath Mountains, NoSN: northern Sierra Nevada, SoCa: } \\
\text { southern California mountains, SoSN: southern Sierra Nevada, Casc } \\
\text { southern Cascade Range. }\end{array}$} \\
\hline
\end{tabular}

\section{DISCUSSION}

\section{Environmental relationships}

We found that avian elevation richness patterns along the PCT have different correlative structures with environmental factors for each of the five montane ecoregions in our comparison (Fig. 2, Table 3). These environmental relationships were independent of generally similar elevation-richness patterns that show midelevation peaks in 4 out of 5 regions between 2000 and 2500 $\mathrm{m}$ (Fig. 3). The mega-transect route captures a wide range of environmental gradients within each region allowing us to elucidate how certain environmental factors may be strongly related to richness in some regions but not others. 
Fig. 3. Relationships of observed avian richness with elevation, by Californian region of the Pacific Crest Trail. Elevation trends of richness (solid black lines) were modeled for each region separately with the elevation at which richness peaks (dotted black lines) were extracted from these models. Klam: Klamath Mountains, Casc: southern Cascade Range, NoSN: northern Sierra Nevada, SoSN: southern Sierra Nevada, SoCa: southern California mountains.

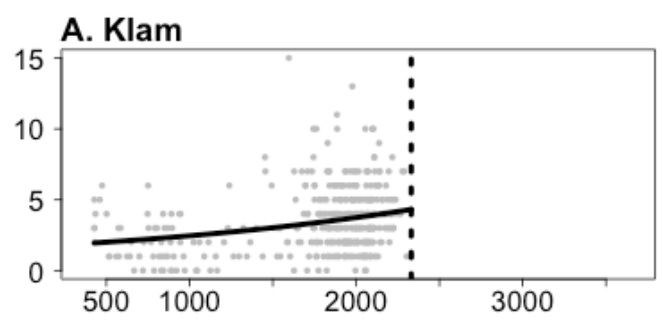

\section{B. Casc}
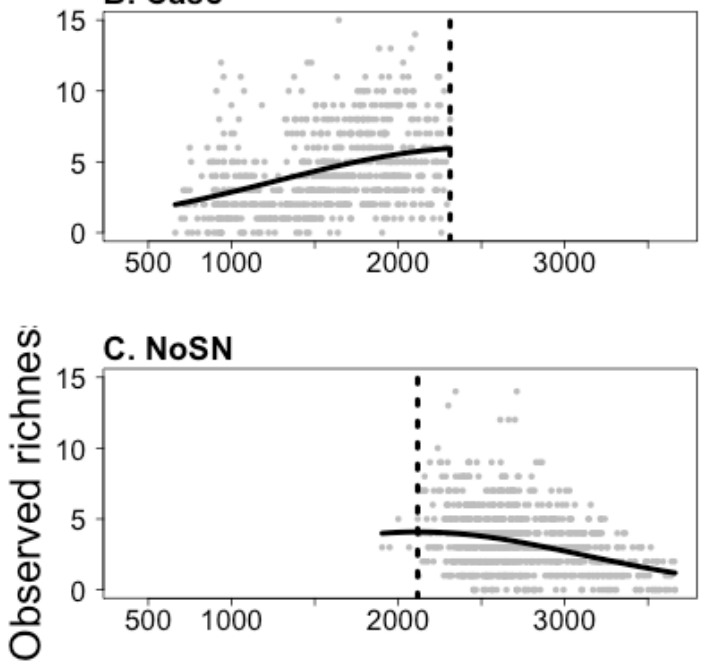

D. SoSN

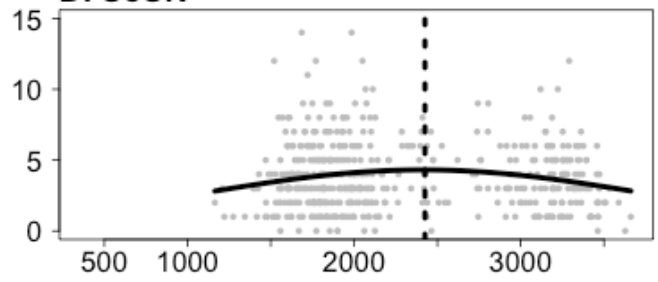

\section{E. SoCa}

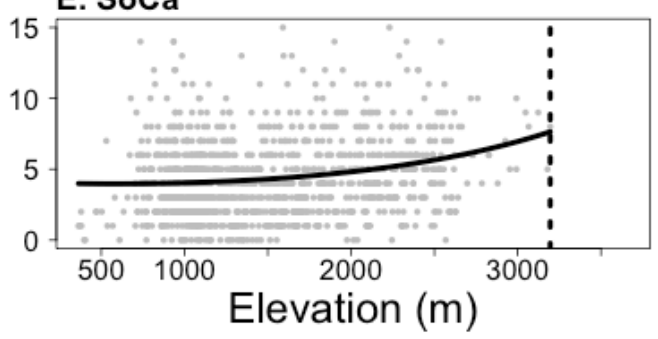

Fig. 4. Patterns of spatial autocorrelation (Moran's I) for raw richness data (red) and residuals of top model including environmental and observational factors (blue). Solid circles represent significant correlations ( $\mathrm{p}<0.01$, Bonferroni corrected for number of distance classes). Dashed line represents zero autocorrelation.

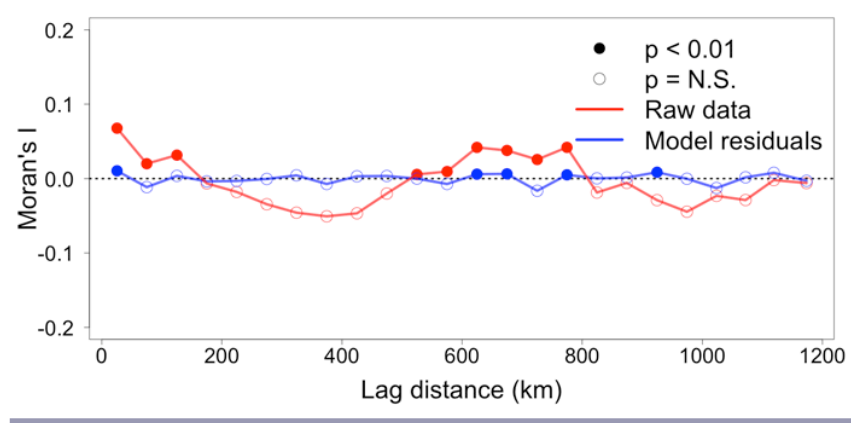

Temperature, for example, had universal model support in the three regions with the lowest elevations (SoCa, Casc, and Klam). Physiological adaptations to specific temperature ranges may limit the number of species able to tolerate extremes at either ends of this temperature gradient (Hawkins et al. 2003, McCain 2009). Interestingly, this relationship may differ across neighboring regions depending on community composition and communitylevel thermal affinities. The comparison of Casc and Klam to SoSN and SoCa are important cases. All four regions extensively sampled hot, low-elevation areas (Fig. 1b), yet the modeled association of richness with temperature showed a significantly positive relationship for SoCa (and a marginal one for $\mathrm{SoSN}$ ) but a negative relationship with the northern regions of Casc and Klam (Fig. 2a). Thus, although temperature is an important correlational driver of richness in three regions, the nature of that relationship differs.

Net primary productivity can also limit species by influencing the vegetation composition and structure of habitats as well as available food resources for birds (Evans et al. 2005). In our results, NDVI held a strong relationship with richness in the three regions that surveyed the highest elevations (SoCa, SoSN, NoSN). This relationship held a primarily quadratic, i.e., unimodal, form, although SoCa, and to a lesser extent SoSN, showed divergence from this trend with a failure to level off in richness at high NDVI values (Fig. 2b). The southern California mountains, with their shallow precipitation gradient and high aridity, appear to not show a saturation effect of richness with increasing NDVI.

Of the environmental gradients explored, precipitation showed the most interesting region-specific relationships. Although precipitation received strong model support in three regions (NoSN, Casc, Klam), the direction of the relationship reversed across the Casc-Klam boundary (Fig. 2c), from positive to negative. It is worth noting that the gradient of precipitation sampled was nearly identical in both Casc and Klam. Precipitation is often used as a surrogate for net primary productivity (Mittelbach et al. 2001), but in certain contexts, precipitation may not adequately reflect productivity, particularly within climates where water is not a limiting factor, or across a 
wide range of climate types (Cusens et al. 2012). The flipped relationship between Casc and Klam could reflect such changes, or could represent the changing nature of precipitation as one moves out of the rain shadow to the east, and toward the coast, across the ecoregional boundary (Fig. 1a,c). It is worth noting that we did not account for the form of precipitation, i.e., rain versus snow, or environmental metrics, such as climatic water deficit, which combine precipitation with other aspects of the environment and which have been shown to be important in structuring changes to plant distributions over time (Crimmins et al. 2011).

Models forecasting the effects of climate warming on species occurrences and richness generally assume that species will respond similarly to climate across their range (Sekercioglu et al. 2008, Stralberg et al. 2009, Wiens et al. 2009, Siegel et al. 2014). Although not all regions in our study area are sampled along the exact same extent in environmental space, regionspecific interactions contrasted with at least one other region where environmental gradients did overlap (Figs. 2a-c). Taken together, these results indicate subtly changing correlates of local avian species richness as one heads north through the mountain ranges traversed by the PCT. This lack of commonality in pattern further reinforces Rowe's (2009) findings on small mammal richness, where it was also observed that no single environmental factor best explained patterns among neighboring mountain regions. Such region-specific relationships with species richness suggest that models that predict diversity changes over time, as with climate change, may not capture local- or region-scale environmental interactions if conducted at the continental scale. Although we found interactions at the scale of approximately $1.5-2^{\circ}$ latitude, it is unknown whether such interactions are more generally expected at larger or smaller scales. Understanding the scale at which diversity interacts with environmental gradients appears to be an important venue for future research.

\section{Addressing inferential challenges and alternative hypotheses}

In any study of drivers of richness, it is critical to account for the many factors that can influence either the formation or the detection of patterns. We explicitly examined sampling effects because of the timing of the surveys, namely time-of-day and time-of-year, and found strong relationships (Fig 2d-f). Observed richness was highest in the early morning hours when bird singing activity was highest. Observed richness also increased toward the end of the field season, perhaps because of increased observer familiarity or the detection of juvenile birds. We show in a separate assessment of this dataset that of 74 common species, just 12 species may have been detected in migration in certain regions (McGrann and Thorne 2014). Despite these relationships with the timing of the surveys, the influence of the environmental variables was still discernable after accounting for these sampling effects in our models.

The species-area relationship may also play a role in shaping species richness patterns. As area generally decreases in a mountain range with increasing elevation, richness is expected to decrease as well. Gamma diversity, or region-wide richness, may be highly influenced by area, but alpha diversity, particularly at small spatial units of this study, is less likely to be influenced by area (McCain 2007). Nevertheless, we explicitly accounted for the available regional richness (Appendix 1) at each site in our models and did not find the relationship to be significant for three of the five regions. Thus, we did not find a strong or consistent effect of the regional richness pool on our observed values of local richness.

We also acknowledge that temperature, precipitation, and net primary productivity are not the only forces potentially shaping diversity patterns along the PCT. Habitat alteration (Forister et al. 2010) has played a significant role in restructuring butterfly communities along the California cordillera. In contrast, the PCT traverses many of the most remote and intact habitats left in California. Although the trail crosses busy highways, our survey methodology ceased counts along the very short sections of trail that passed through anthropogenically developed areas.

\section{CONCLUSIONS}

Across our five ecological regions along the PCT on the California cordillera, we found that three environmental factors (temperature, precipitation, and net primary productivity) varied in importance as correlates of avian richness. Avian richness responded differently along elevation gradients in the semiarid climate of Southern California, in the more mesic climates of the Klamath and Cascade ranges, and in the two high-elevation Sierra Nevada regions. We found no single pattern that explained correlative structures of environment and avian richness across latitude, and some correlations between richness and environmental factors had opposite signs in adjacent regions (e. g., Casc and Klam).

Montane birds are particularly sensitive to projected shifts in temperature and precipitation, and the area-elevation relationship of mountains is expected to leave less room for birds to track the climate trends of the future if increasing temperatures shift them upslope (Sekercioglu et al. 2008, La Sorte and Jetz 2010). Evidence has demonstrated, however, that elevation shifts of the recent past have been both upslope and downslope as bird species locally track temperature and precipitation changes, often in directions that show regional-scale variability in associations with temperature versus precipitation (Tingley et al. 2009, 2012). Our results of current richness-environment relationships support this observation that local- or regional-scale climatic associations can strongly structure bird communities.

Our study area engages a wide range of potential stakeholders and actors for regional conservation efforts. The ownership of lands along the PCT is diverse, including private lands, state and federal parks, national forests, and wilderness areas. Our results suggest that a "one size fits all" approach to climate change adaptation for birds on mountains is inappropriate. If climatic associations with communities can switch over short geographic distances, then species distribution modeling, conservation planning, species prioritization, and adaptation strategies are best done at the local to regional scale with coordination among agencies, conservation organizations, and private citizens (Heller and Zavaleta 2009), and not applied uniformly across broad areas, even contiguous mountain chains. We suggest that it is critical to consider the intrinsic local- and regional-scale environmental factors, such as the specific climate of a mountain region, in conservation efforts anticipating the effects of future climate change on avian communities. 
Responses to this article can be read online at: http://www.ace-eco.org/issues/responses.php/695

\begin{abstract}
Acknowledgments:
This study was partly funded by a Selma Herr endowment grant from the Department of Wildlife, Fish and Conservation Biology at the University of California, Davis. We are grateful to the Herr family for their financial support. M. Tingley was supported by a David H. Smith Conservation Research Fellowship. Michelle Koo and Chris Daily generously provided PRISM climate grids. We thank two anonymous reviewers for their useful comments. The field component of this study could not have been accomplished without the aid and support of many individuals.
\end{abstract}

\section{LITERATURE CITED}

Anderson, A. S., C. J. Storlie, L. P. Shoo, R. G. Pearson, and S. E. Williams. 2013. Current analogues of future climate indicate the likely response of a sensitive montane tropical avifauna to a warming world. PLoS ONE 8:e69393. http://dx.doi.org/10.1371/ journal.pone.0069393

Bjornstad, O. N. 2012. ncf: spatial nonparametric covariance functions. $\mathrm{R}$ package version 1.1-4. R Project for Statistical Computing, Vienna, Austria. [online] URL: http://cran.r-project. org/web/packages/ncf/

Burnham, K. P., and D. R. Anderson. 2002. Model selection and multimodel inference. Springer, New York, New York, USA. http://dx.doi.org/10.1007/b97636

California Department of Fish and Wildlife. 2008. CWHR version 8.2 personal computer program. California Interagency Wildlife Task Group, Sacramento, California, USA. [online] URL: https:// www.dfg.ca.gov/biogeodata/cwhr/

Crimmins, S. M., S. Z. Dobrawski, J. A. Greenberg, J. T. Abatzoglou, and A. R. Mynsberge. 2011. Changes in climatic water balance drive downhill shifts in plant species' optimum elevations. Science 331:324-327. http://dx.doi.org/10.1126/ science. 1199040

Cusens, J., S. D. Wright, P. D. McBride, and L. N. Gillman. 2012. What is the form of the productivity-animal-species-richness relationship? A critical review and meta-analysis. Ecology 93:2241-2252. http://dx.doi.org/10.1890/11-1861.1

Daly, C., M. Halbleib, J. I. Smith, W. P. Gibson, M. K. Doggett, G. H. Taylor, J. Curtis, and P. P. Pasteris. 2008. Physiographically sensitive mapping of climatological temperature and precipitation across the conterminous United States. International Journal of Climatology 28:2031-2064. http://dx.doi. org/10.1002/joc. 1688

DesGranges, J., and M. LeBlanc. 2012. The influence of summer climate on avian community composition in the eastern boreal forest of Canada. Avian Conservation and Ecology 7(1): 2. http:// dx.doi.org/10.5751/ACE-00512-070102

Dolanc, C. R., J. H. Thorne, and H. D. Safford. 2013. Widespread shifts in the demographic structure of subalpine conifer forests over last 80 years in the central Sierra Nevada. Global Ecology and Biogeography 22:264-276. http://dx.doi.org/10.1111/ j.1466-8238.2011.00748.x

Evans, K. L., P. H. Warren, and K. J. Gaston. 2005. Species-energy relationships at the macroecological scale: a review of the mechanisms. Biological Reviews 80:1-25. http://dx.doi.org/10.1017/ S1464793104006517

Forister, M. L., A. C. McCall, N. J. Sanders, J. A. Fordyce, J. H. Thorne, J. O'Brien, D. P. Waetjen, and A. M. Shapiro. 2010. Compounded effects of climate change and habitat alteration shift patterns of butterfly diversity. Proceedings of the National Academy of Sciences of the United States of America 107:2088-2092. http://dx.doi.org/10.1073/pnas.0909686107

Gotelli, N. J., and R. K. Colwell. 2001. Quantifying biodiversity: procedures and pitfalls in the measurement and comparison of species richness. Ecological Letters 4:379-391. http://dx.doi. org/10.1046/j.1461-0248.2001.00230.x

Hawkins, B. A., R. Field, H. V. Cornell, D. J. Currie, J.-F. Guégan, D. M. Kaufman, J. T. Kerr, G. G. Mittelbach, T. Oberdorff, E. M. O'Brien, E. E. Porter, and J. R. G. Turner. 2003. Energy, water, and broad-scale geographic patterns of species richness. Ecology 84:3105-3117. http://dx.doi.org/10.1890/03-8006

Hayhoe, K., D. Cayan, C. B. Field, P. C. Frumhoff, E. P. Maurer, N. L. Miller, S. C. Moser, S. H. Schneider, K. N. Cahill, E. E. Cleland, L. Dale, R. Drapek, R. M. Hanemann, L. S. Kalkstein, J. Lenihan, C. K. Lunch, R. P. Neilson, S. C. Sheridan, and J. H. Verville. 2004. Emissions pathways, climate change, and impacts on California. Proceedings of the National Academy of the Sciences of the United States of America 101:12422-12427. http:// dx.doi.org/10.1073/pnas.0404500101

Heller, N. E., and E. S. Zavaleta. 2009. Biodiversity management in the face of climate change: a review of 22 years of recommendations. Biological Conservation 142:14-32. http://dx. doi.org/10.1016/j.biocon.2008.10.006

Honkanen, M., J.-M. Roberge, A. Rajasärkkä, and M. Mönkkönen. 2010. Disentangling the effects of area, energy and habitat heterogeneity on boreal forest bird species richness in protected areas. Global Ecology and Biogeography 19:61-71. http://dx.doi.org/10.1111/j.1466-8238.2009.00491.x

Intergovernmental Panel on Climate Change (IPCC). 2007. Climate change 2007: synthesis report. Contribution of Working Groups I, II, and III to the Fourth Assessment Report of the Intergovernmental Panel on Climate Change. Core Writing Team, R. K. Pachauri, and A. Reisinger, editors. IPCC, Geneva, Switzerland.

Jensen, J. R. 2007. Remote sensing of the environment. Pearson Prentice Hall, Upper Saddle River, New Jersey, USA.

Körner, C. 2007. The use of 'altitude' in ecological research. Trends in Ecology and Evolution 22:569-574. http://dx.doi. org/10.1016/j.tree.2007.09.006

La Sorte, F. A., and W. Jetz. 2010. Projected range contractions of montane biodiversity under global warming. Proceedings of the Royal Society B-Biological Sciences 277:3401-3410. http://dx. doi.org/10.1098/rspb.2010.0612 
Lee, P., T. Ding, F. Hsu, and S. Geng. 2004. Breeding bird species richness in Taiwan: distribution on gradients of elevation, primary productivity and urbanization. Journal of Biogeography 31:307-314. http://dx.doi.org/10.1046/j.0305-0270.2003.00988.x

McCain, C. M. 2007. Area and mammalian elevation diversity. Ecology 88:76-86. http://dx.doi.org/10.1890/0012-9658(2007)88 [76:AAMED]2.0.CO;2

McCain, C. M. 2009. Global analysis of bird elevation diversity. Global Ecology and Biogeography 18:346-360. http://dx.doi. org/10.1111/j.1466-8238.2008.00443.X

McGrann, M. C., and J. H. Thorne. 2014. Elevation ranges of birds along California's Pacific Crest Trail. Western Birds 45:18-42.

Miles, S. R., and C. B. Goudy. 1997. Ecological subregions of California: section and subsection descriptions. R5-EM-TP-005, U.S. Forest Service, Pacific Southwest Region, San Francisco, California, USA.

Mittelbach, G. G., C. F. Steiner, S. M. Scheiner, K. L. Gross, H. L. Reynolds, R. B. Waide, M. R. Willig, S. I. Dodson, and L. Gough. 2001. What is the observed relationship between species richness and productivity? Ecology 82:2381-2396. http://dx.doi. org/10.1890/0012-9658(2001)082[2381:WITORB]2.0.CO;2

R Development Core Team 2014. R: a language and environment for statistical computing. R Foundation for Statistical Computing, Vienna, Austria.

Rahbek, C. 2005. The role of spatial scale and the perception of large-scale species-richness patterns. Ecological Letters 8:224-239. http://dx.doi.org/10.1111/j.1461-0248.2004.00701.x

Ralph, C. J., J. R. Sauer, and S. Droege. 1995. Monitoring bird populations by point counts. PSW-GTR-149. U.S. Forest Service, Pacific Southwest Research Station, Albany, California, USA.

Ricklefs, R. E. 2000. The relationship between local and regional species richness in birds of the Caribbean Basin. Journal of Animal Ecology 69:1111-1116. http://dx.doi.org/10.1111/j.1365-2656.2000.00456. $\mathrm{x}$

Rowe, R. J. 2009. Environmental and geometric drivers of small mammal diversity along elevation gradients in Utah. Ecography 32:411-422. http://dx.doi.org/10.1111/j.1600-0587.2008.05538.x

Ruggiero, A., and B. A. Hawkins. 2008. Why do mountains support so many species of birds? Ecography 31:306-315. http:// dx.doi.org/10.1111/j.0906-7590.2008.05333.x

Sanders, N. J., and C. Rahbek. 2012. The patterns and causes of elevation diversity gradients. Ecography 35:1-3. http://dx.doi. org/10.1111/j.1600-0587.2011.07338.x

Sekercioglu, C. H., S. H. Schneider, J. P. Fay, and S. R. Loarie. 2008. Climate change, elevation range shifts, and bird extinctions. Conservation Biology 22:140-150. http://dx.doi.org/10.1111/ j.1523-1739.2007.00852.x
Siegel, R. B., P. Pyle, J. H. Thorne, A. J. Holguin, C. A. Howell, S. Stock, and M. W. Tingley. 2014. Vulnerability of birds to climate change in California's Sierra Nevada. Avian Conservation and Ecology 9(1): 7. http://dx.doi.org/10.5751/ACE-00658-090107

Snyder, M. A., J. L. Bell, L. C. Sloan, P. B. Duffy, and B. Govindasamy. 2002. Climate responses to a doubling of atmospheric carbon dioxide for a climatically vulnerable region. Geophysical Research Letters 29:9-1-9-4. http://dx.doi. org/10.1029/2001GL014431

Stralberg, D., D. Jongsomjit, C. A. Howell, M. A. Snyder, J. D. Alexander, J. A. Wiens, and T. L. Root. 2009. Re-shuffling of species with climate disruption: a no-analog future for California birds? PLOS ONE 4:e6825. http://dx.doi.org/10.1371/journal. pone. 0006825

Thorne, J. H., B. J. Morgan, and J. A. Kennedy. 2008. Vegetation change over sixty years in the Central Sierra Nevada, California, USA. Madroño 55:223-237. http://dx.doi.org/10.3120/0024-9637-55.3.223

Tingley, M. W., and S. R. Beissinger. 2013. Cryptic loss of montane avian richness and high community turnover over 100 years. Ecology 94:598-609. http://dx.doi.org/10.1890/12-0928.1

Tingley, M. W., M. S. Koo, C. Moritz, A. C. Rush, and S. R. Beissinger. 2012. The push and pull of climate change causes heterogeneous shifts in avian elevation ranges. Global Change Biology 18:3279-3290. http://dx.doi.org/10.1111/j.1365-2486.2012.02784.

\section{$\mathrm{x}$}

Tingley, M. W., W. B. Monahan, S. R. Beissinger, and C. Moritz. 2009. Birds track their Grinnellian niche through a century of climate change. Proceedings of the National Academy of Sciences of the United States of America 106 Suppl 2:19637-19643. http:// dx.doi.org/10.1073/pnas.0901562106

Venables, W. N., and B. D. Ripley. 2002. Modern applied statistics with $S$. Fourth Edition. Springer, New York, New York, USA. http://dx.doi.org/10.1007/978-0-387-21706-2

White, E. P., and A. H. Hurlbert. 2010. The combined influence of the local environment and regional enrichment on bird species richness. American Naturalist 175:E35-E43. http://dx.doi. org/10.1086/649578

Wiens, J. A., D. Stralberg, D. Jongsomjit, C. A. Howell, and M. A. Snyder. 2009. Niches, models, and climate change: assessing the assumptions and uncertainties. Proceedings of the National Academy of Sciences of the United States of America 106 Suppl 2:19729-19736. http://dx.doi.org/10.1073/pnas.0901639106

Zuur, A. F., E. N. Ieno, and G. M. Smith. 2007. Analysing ecological data. Springer, New York, New York, USA. http://dx. doi.org/10.1007/978-0-387-45972-1
Editor-in-Chief: Keith A.Hobson

Subject Editor: Erin Bayne
Sponsored by the Society of Canadian Ornithologists and Bird Studies Canada Parrainée par la Société des ornithologistes $d u$ Canada et Etudes d'oiseaux Canada

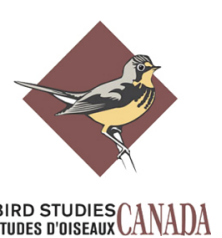


Appendix 1. Method for calculating the regional species richness pool and map of regional species richness for California.

\section{Background}

Studies seeking to explore the relationships of community metrics such as richness or abundance to local environments risk overstating correlations if the role of the regional species pool is not additionally incorporated into analyses (White and Hurlbert 2010). The regional richness pool (an estimate of gamma diversity) represents that maximum alpha diversity attainable at a locality, and thus can strongly influence how many species are actually observed at sites. For this reason, we incorporated an index of the regional richness pool at each site as a sampling covariate in all our models of local richness and abundance. The calculation of the regional richness pool is not a simple process. A standard and recommended approach is to layer expert-derived range maps, resulting in a potential richness layer (Ricklefs 2000). There can be a large discrepancy between the pool of species available at a site and the actual number of species observed within a region (i.e., observed gamma diversity) due to habitat heterogeneity and localized holes in species' ranges (Hurlbert and White 2005). However, we follow White and Hurlbert (2010), in using range maps as the best available measure of the regional richness pool.

\section{Methods}

The regional species pool at each location was estimated by intersecting survey points with California Wildlife Habitat Relationship System (CWHR) range maps (California Department of Fish and Wildlife 2008) for all 155 bird species detected at least once in our surveys. CWHR range maps combine occurrence-data and expert opinion to derive vectorbased, season-specific range maps for 864 bird species that are known to occur in California. CWHR range maps are the best available approximation of true ranges for birds within the state.

For each bird species, we used only the range identified as either "summer" (i.e., breedingseason) or "year-round." Vector-based range maps were converted to a $1 \mathrm{~km}^{2}$ raster grid and layered. Rasters share their resolution with the PRISM climate data used in this analysis. The number of species with ranges intersecting each grid cell was summed. The resultant surface (Fig. A1) was intersected with survey points to derive the regional species pool variable at each location.

\section{Literature Cited}

California Department of Fish and Wildlife. 2008. CWHR version 8.2 personal computer program. California Interagency Wildlife Task Group, Sacramento, California, USA. URL: https://www.dfg.ca.gov/biogeodata/cwhr/

Hurlbert, A. H., and E. P. White. 2005. Disparity between range map- and survey-based analyses of species richness: patterns, processes and implications. Ecological Letters 8:319327.

Ricklefs, R. E. 2000. The relationship between local and regional species richness in birds of the Caribbean Basin. Journal of Animal Ecology 69:1111-1116. 
White, E. P., and A. H. Hurlbert. 2010. The combined influence of the local environment and regional enrichment on bird species richness. The American Naturalist 175:E35-E43.

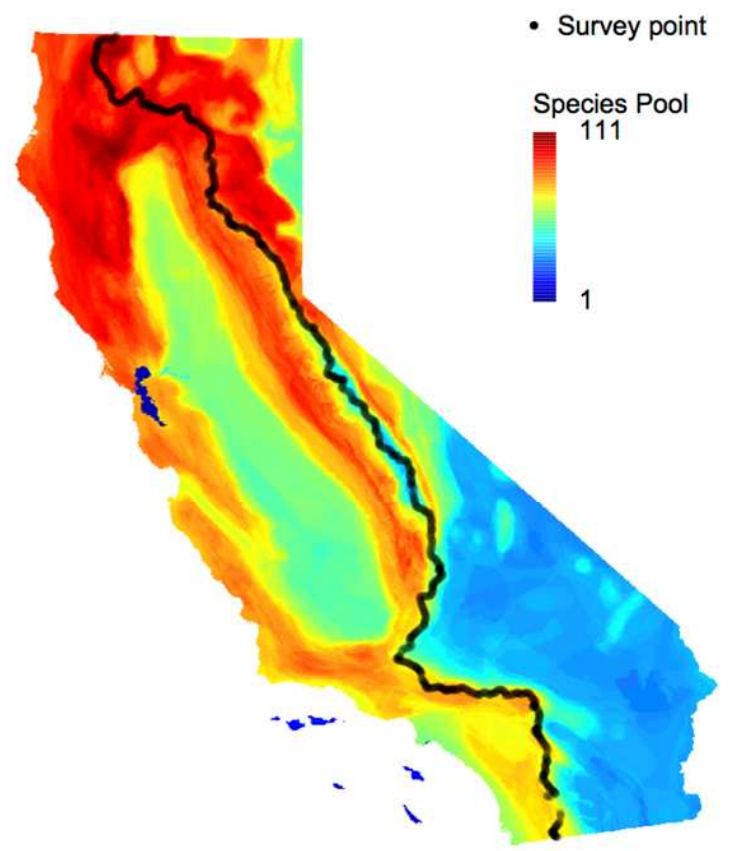

Figure A1. Available species richness pool for California as derived from expert-based range maps for 155 species detected at least once during surveys along PCT. 
Appendix 2. Using supplemental data from 2007 to evaluate survey sample completeness.

\section{Background and Methods}

Point samples of bird community richness are by nature assumed to be incomplete. Thus, the observed bird richness during a 5-minute point count is expected to be a fraction of the true species richness that occurs at a site, which is a fraction of the regional species pool (Hurlbert and White 2005). There are numerous reasons why a 5-minute sample of a community is expected to be incomplete, but with bird surveys, the main factors are considered to be imperfect detection of species present at the site, combined with species moving around such that some individuals that truly occupy a site are not available for sampling during the duration of the survey. The incomplete detection of species during surveys can result in richness estimates that produce biased patterns and inference (Tingley and Beissinger 2013). Here, we use supplemental survey data collected at a subsample of sites in 2007 to evaluate the degree to which our 5-minute surveys conducted at all sites in 2006 either completely or incompletely sampled bird richness.

In 2007, one observer (MCM) returned to a 150 high-elevation sites along the PCT and conducted additional bird surveys. Revisited sites were distributed across all 5 regions of the PCT, but were concentrated in NoSN (92 sites) and SoSN (40 sites) where the PCT reaches its highest elevations. At each site, a single consecutive bird survey was conducted, totaling 120 minutes, divided into a 30, 60, and the full 120-minute increment. During the first 30minutes, all bird species detected were recording. During the following 30- and 60-minute segments, only new species detections were recorded. During the full 120 minutes, the observer (MCM) was also collecting vegetation data, but as most bird detections are auditory, this is not expected to substantially bias species lists. Richness estimates derived from species lists during these supplemental, extended sampling visits were used to explore the extent to which species detected during 5-minute visits to sites in 2006 were complete or incomplete.

\section{Results and Discussion}

Species richness samples derived from 5-minute surveys showed varying degrees of completeness (Fig. A2). At $43 \%$ of survey locations, 5 -minute surveys sampled $100 \%$ of species detected during 30 -minute surveys. This percentage dropped to $20 \%$ for 60 -minute surveys, and $4 \%$ for 120 -minute surveys. The median percentage of species detected during 5 -minute surveys was $75 \%, 58 \%$, and $40 \%$, compared to $30-, 60$-, and 120 -minute surveys, respectively.

Despite evidence that 5-minute surveys incompletely sampled the bird community, particularly when compared to 120-minute samples, we found strong relationships between the percentage of sample completeness and both the time-of-day and time-of-year of the 5minute samples (Fig. A2). Across 30-, 60-, and 120-minute survey durations, the proportion of species detected during 5-minutes was near perfect early in the breeding season and early in the morning (Fig. A2), times when bird detectability is expected to be high. Put together in a generalized linear model (binomial error distribution with log link), the time-of-day was linearly significant $(p<0.01)$ in explaining richness proportions of all three extended durations, and the time-of-year had a significant positive quadratic (i.e., bowl-shaped) relationship for the proportion of species detected compared to 30- and 60-minute surveys. 
While the analysis of supplemental extended surveys collected in 2007 indicates that 5-minute surveys conducted along the PCT incompletely sampled the bird community, this analysis also indicates that the potential for this "detection gap" to bias our main findings is minimal. First, the number of species detected during 5-minutes was significantly correlated with the number of species detected over 60- $(p=0.002)$ and 120-minutes $(p<0.001)$, and marginally correlated with the number of species detected over 30-minutes $(p=0.075)$. Given this tight correlation (particularly with regard to a full 120-minute survey), the forms of statistical relationships derived from 5-minute survey data are not likely to significantly differ from those derived from 120-minute survey data. Second, as the degree to which 5minute surveys incompletely sampled local bird richness was significantly related to time-ofyear and time-of-day, adding these two variables into our models of local species richness should help correct for sampling bias. Indeed, the statistical relationships modeled for timeof-day and time-of-year based off of the full 2006 dataset (see main text, Fig. 2), closely match the proportional incompleteness relationships modeled here (Fig. A2).

\section{Literature Cited}

Hurlbert, A. H., and E. P. White. 2005. Disparity between range map- and survey-based analyses of species richness: patterns, processes and implications. Ecological Letters 8:319327.

Tingley, M. W., and S. R. Beissinger. 2013. Cryptic loss of montane avian richness and high community turnover over 100 years. Ecology 94:598-609.
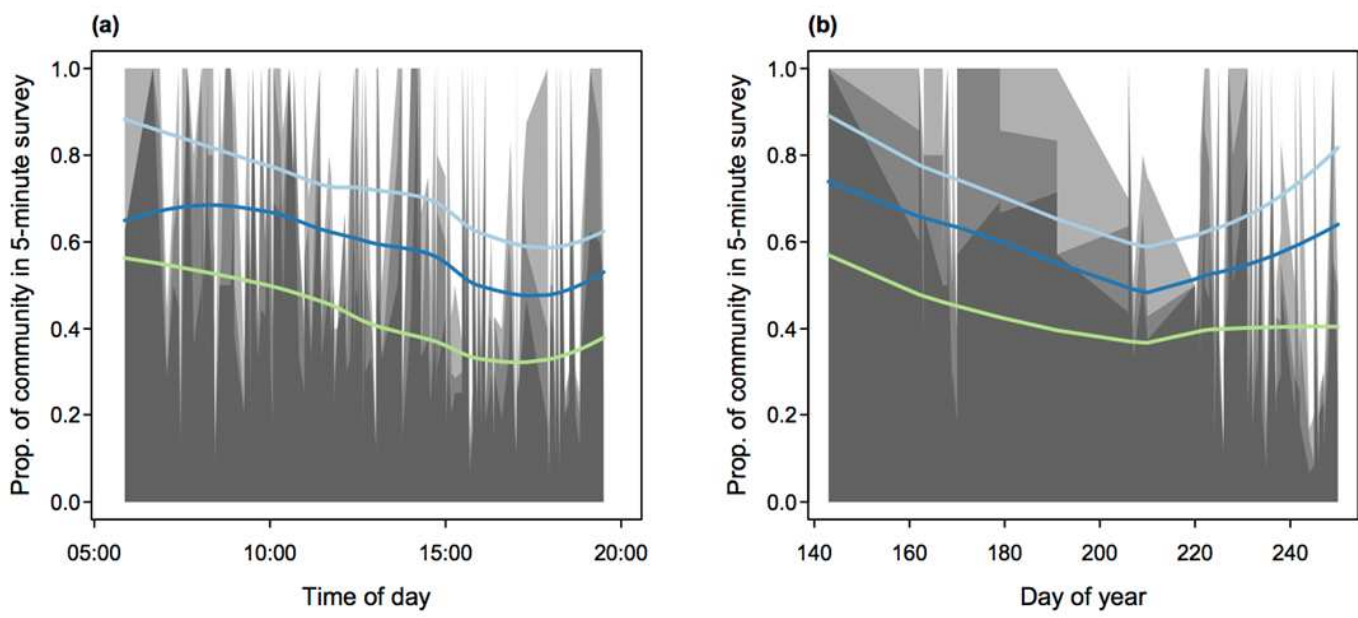

Figure A2. The proportion of bird species richness detected during 5-minute survey, in relation to the time-of-day (a) and the day of year (b). Proportions are relative to 30-minute (light gray), 60-minute (medium gray), and 120-minute (dark gray) bird surveys at 150 sites. Loess curves for 30- (light blue), 60- (dark blue), and 120-minute (light green) surveys show trends in proportions in relation to time-of-day and day of year. 